\title{
Device for nanoparticle production using plasma methods ${ }^{(\bullet)}$
}

\author{
$\operatorname{Ioan~Bica~}^{(*)}$
}

\begin{abstract}
The paper presents a device for nanoparticle production using the method of vaporization of metals and/or the method of thermal decomposition of compounds of metals (oxides, carbonyls, halides, etc.) in the plasma of transferred electric arc or in plasma jet. The dimensions particles obtained are 3 to $100 \mathrm{~nm}$ some possible applications.
\end{abstract}

Keywords Nanoparticles. Plasma. Plasma jet. Thermal decomposition. Iron. Graphite.

\section{Dispositivo para la producción de nanopartículas a través de un proceso con plasma}

\begin{abstract}
Resumen Este trabajo presenta un dispositivo destinado a la producción de nanopartículas utilizando métodos de vaporización de metales y/o el método de descomposición de compuestos metálicos ( óxidos, carbonatos, halógenos ) en el plasma del arco transferido o en el chorro de plasma. Se presentan algunas posibles aplicaciones. Las dimensiones de las partículas obtenidas varían entre 3 y $100 \mathrm{~nm}$.
\end{abstract}

Palabras clave: Nanopartículas. Plasma. Ahorro de plasma. Disociación. Hierro. Grafito.

\section{INTRODUCTION}

Particles of dimensions between $1 \mathrm{~nm}$ and $100 \mathrm{~nm}$ are called nanoparticles (1). They are comprised, according to (2), in the transmission domain between micro- and macrocosmos, specific to the great majority of phenomena related to living organisms.

Ferrite nanoparticles were found in the brain as well as in bacteria (2) and it is supposed to play a major role in the orientation of birds along the magnetic field of the Earth. Moreover, such nanoparticles are used in microbiology to separate endrocythes and in food industry as catalytic agents.

Nanoparticles are of interest especially in relation to production of new materials (3-5). E.g., their magnetic properties may be useful for preparation of specific mesoscopic liquids (magnetic fluids) (6). Also, distributed in solid matrices, using the methods described in (7), they

\footnotetext{
$(\bullet \quad$ Trabajo recibido el día 5 de Octubre de 1998 y aceptado en su forma final el día 26 de Febrero de 1999.

(*) Departament of Physics, Weat University of Timisoara;
} Bd. Vasile Parvan, 1900. Timisoara (RUMANÍA) could serve to produce various high performance electronic devices (8). Applying well known specific methods nanoglasses, nanoceramics and nanomagnets, etc. are obtained (9). Iron carbide nanoparticles in liquid carriers are useful for medical diagnostics (10) and the list of applications may be continued.

The increasing need for nanomaterials with competitive properties motivated research orientated on the construction of specific installations for production of nanoparticles with prestablished dimensions and chemical composition. Various installations were constructed for nanoparticle production, using laser radiation for metal vaporization (11), TIG arc (12 and 13) and MIG arc (14), as well as magnetron type discharges (15).

Nanoparticles were produced also by thermal decomposition of metal halides in plasma (16) and of organometallic compounds in capacitive plasma (17). The particles produced have various dimensions, geometrical forms and chemical compositions (11-18 and 20-22). At present much effort is directed on the construction of specialized installations for nanoparticle productions with well defined characteristics. The main component of 
such an installation is the device for nanoparticles production. This paper presents the construction and characteristics of such an experimental device.

\section{EXPERIMENTAL PROCEDURE}

The device constructed for nanoparticle production (Fig. 1) has a d.c. plasma generator and a vaporizing chamber. The cathode of the plasma generator is provided with a pressure equalizing chamber 1 for the plasmagen gas (Ar), a system of pincers 2 , with wolfram electrode 3 , as well as an electrode holder with cooling chamber 4 . The plasma generator has a cooling chamber 5 , a pressure equalizing chamber 6 for transporting gas and a nozzle 7 . The electrode 3 is galvanically insulated from the generator nozzle through the polyamid insulator. The thermal insulation is ensured by the ceramic piece 9 . The rings 11 and 12 are seals. The water and gas circuits are shown in figure 1 . The vaporizing chamber is intensively cooled and has external diameter of $134 \mathrm{~mm}$ and internal diameter of $114 \mathrm{~mm}$. It has two lateral openings 13 and 14.

The first opening has the transparent window 15 for direct view on the process, while the second one with the connection 16 is for the evacuation of particles into the collecting chamber. The rings of graphitezed teflon 17 and 18 (Fig. 1) have the role of seals.

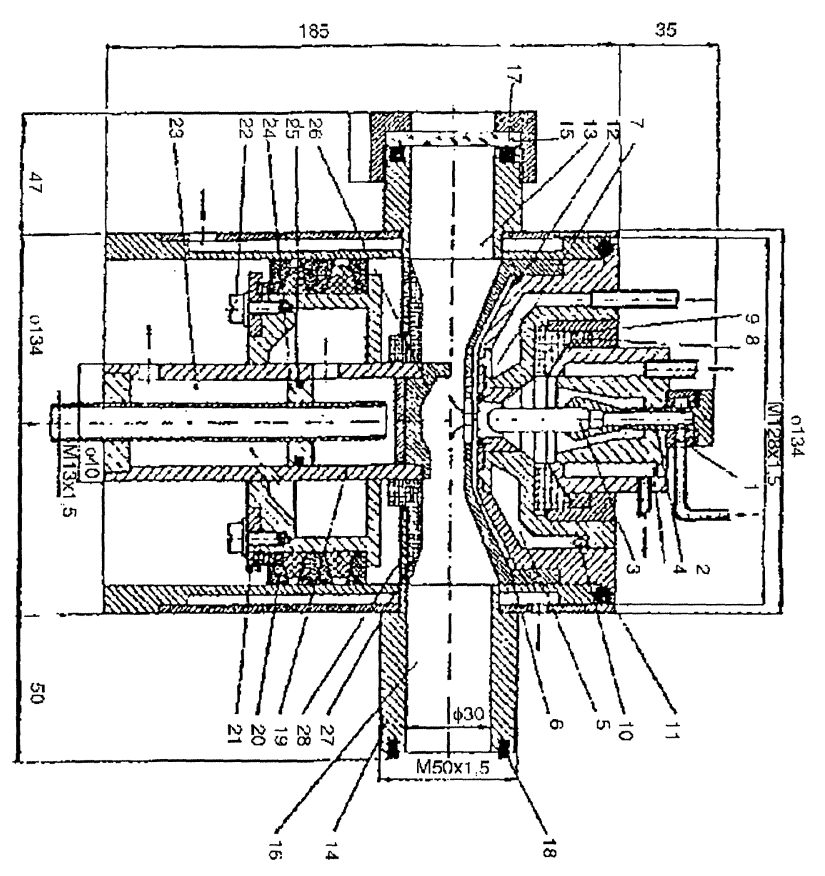

FIG. 1.- Experimental equipment.

FIG. 1.- Equipo experimental.
The semimobile anode 19 (Fig. 1) is intensively cooled. The sealing rings 20 maintain the working pressure in the vaporizing chamber and are ensured by the tightening pieces 21 and 22 .

The separation of cooling chambers 23 is provided by the piston 24 with the sealing ring 25 . The crucible 26, mounted on the semimobile anode, is interchangeable.

In the operating mode, in transferred arch regime, the crucible 26 is replaced by the iron piece $(\varnothing 34 \times 40 \mathrm{~mm}$ ). This consists of the material to be vaporized. The sealing rings 20 are protected against the action of hot gases through the ceramic insulator 27, fixed on the holder 28 .

The collecting chamber (Fig. 2) is the assembly of cylinders 1 and 2 . Cooling water flows between walls 3 and 4 of these cylinders, which enters the inlet 5 . The chamber assembly is mounted on the rings 6 and 7. The seals 8 and 9 are resistent to water and gas pressure. The electric drive 10 allows to rotate the chamber around the axis 11 on the support 12. The liquid matrix 13 is introduced through the inlet 14 and wets the inner walls of the chamber, collecting the particles deposited there.

The chamber is connected to the vaporisation chamber, as well as to the vacuum pump, through the junctions 15 and 16. The chamber contains the bored cylinder 17 elastically mounted on the distance pieces 18 and the spring 19. The blades 20 are introduced in the cylinder 17 in order to enlarge the path of gas carried particles in the chamber.

A central control unit provides:

- constant pressure in the vaporisation chamber,

- uniform rate of materials in the plasma jet,

- constant discharge current,

- temperature control in the cooling system.

Preliminary experiments (11 and 13) revealed that the relative pressure in the vaporisation chamber may be between $-100 \mathrm{kPa}$ and $5 \mathrm{MPa}$. The depression is made with a vacuum pump (flow rate $1 \cdot 10^{-3} \mathrm{Nm}^{3}\left(\mathrm{~s}^{-1}\right)$, while the overpressure is taken from condensed gas recipients.

When negative relative pressure is established in the chamber, the minimum argon flow rate in the pole nozzle region of the plasma generator should be $1 / 12\left(10^{-3} \mathrm{Nm}^{3} \cdot \mathrm{s}^{-1}\right.$. The flow rate is controlled using the rotameter fixed on the gas recipient. For the maximum discharge power $\left(30 \cdot 10^{3} \mathrm{~W}\right)$ the required minimum cooling water flow rate was found experimentally:

$0.25 \cdot 10^{-3} \mathrm{Nm}^{3} \cdot \mathrm{s}^{-1}$ in the cathode circuit and the circuit of the powder collecting chamber $0.5 \cdot 10^{-3} \mathrm{Nm}^{3} \cdot \mathrm{s}^{-1}$ in the nozzle circuit $0.75 \cdot 10^{-3} \mathrm{Nm}^{3} \cdot \mathrm{s}^{-1}$ in the semimobile anode circuit 


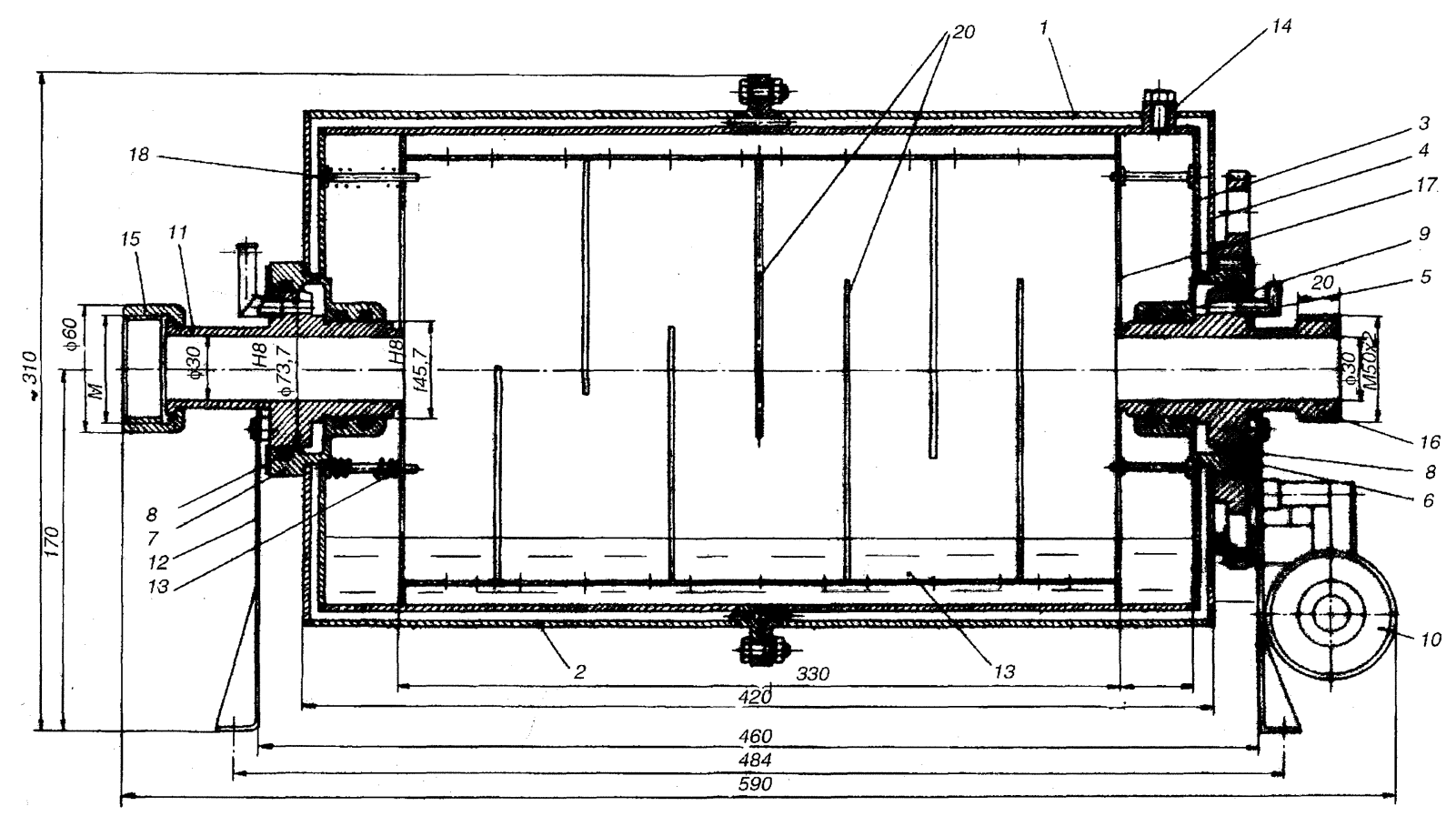

FIG. 2.- Powder collecting chamber.

FIG. 2.-Cámara de recogida de polvos.

The samples are positioned on a special support and examined with the transmission electron microscope BS 613, with acceleration voltage 100 $\mathrm{kW}$. In order to avoid the premature ageing, the samples are cooled into liquid nitrogen using a special device mounted in the microscope chamber. Sample images are recorded on photographic plates, which are magnified in order to determine the particle sizes. This investigation procedure allows to evidentiate particles of minimum $0.7 \mathrm{~nm}$ size. Dimensional distributions are recovered after examination of 1,500-2,000 particles (Figs. 3 and 4). The size of all particles are in the range 3-100 nm (Figs. 3 and 4).

\section{POSSIBLE OPERATION REGIMES}

\subsection{Transferred arc regime}

In the transferred arc regime, the electric arc plasma is transferred from the nozzle 7 (Fig. 1) on the half finished product placed on the semimobile anode 13 , instead of on the crucible 26 . The meeting of the half finished product, followed by its vaporisation, occurs at the discharge current 350 $\mathrm{A}_{\mathrm{dc}}$ in argon on helium gas medium. The metal vapours are trained by the plasmagen arc and condense on the gas particles. Because of the surface tension, metal liquid drops of spherical

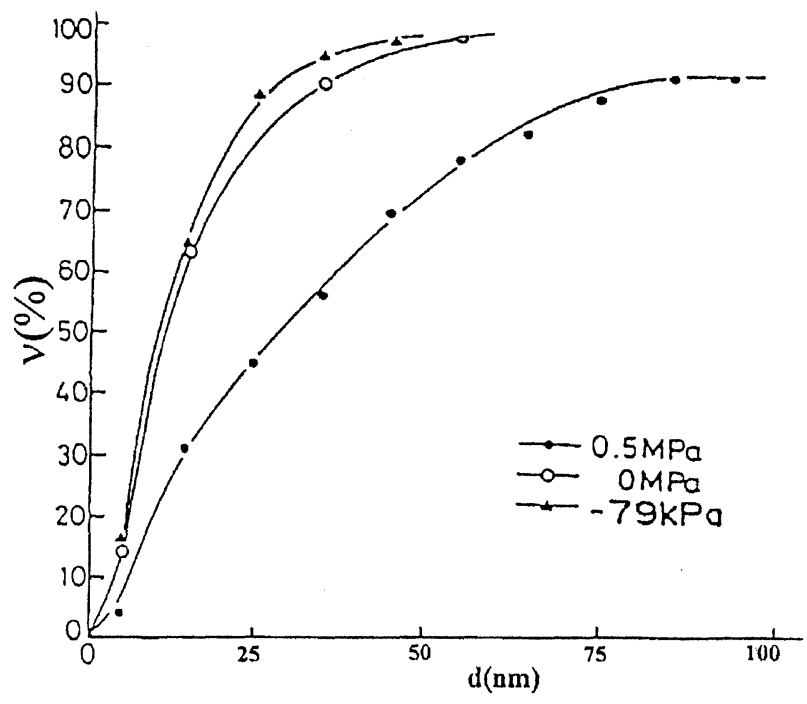

FIG. 3.- Dimensional distribution of iron nanoparticles. Plasmagen gas: Ar. Intensity of electric current: $350 \mathrm{~A}(\mathrm{dc})$.

FIG. 3.- Distribución dimensional de las nanpartículas de hierro en plasma de argón. Intensidad de la corriente de descarga: $350 \mathrm{~A}$ (cc).

shape are formed. These drops become solid particles in those areas of the chamber whose temperature is lower, and are trained by the gas into the collecting chamber (Fig. 2), being collected in the liquid matrix. 


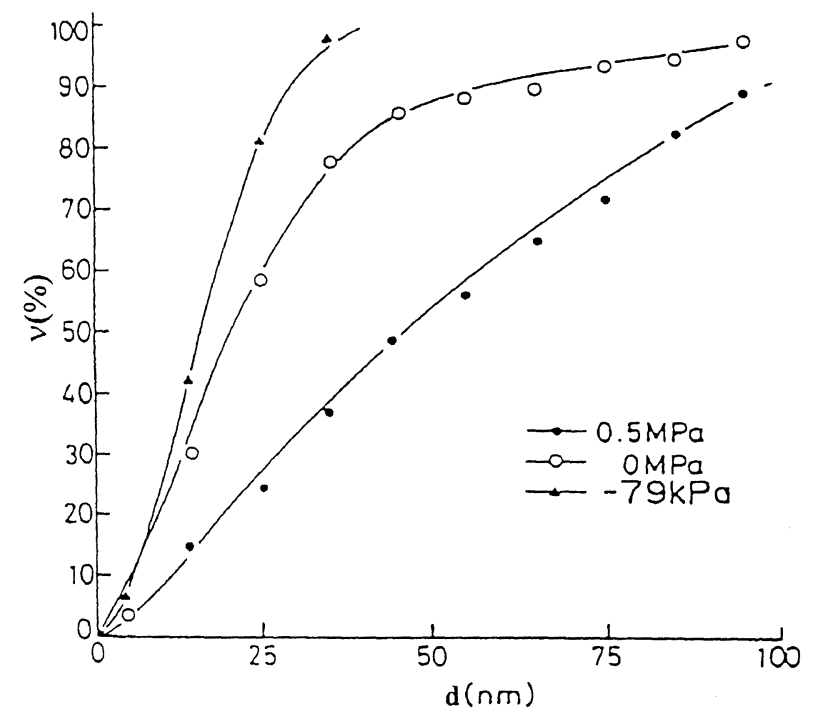

FIG. 4.- Dimensional distribution of iron nanoparticles. Plasmagen gas: He. Intensity of electric current: $350 \mathrm{~A}(\mathrm{dc})$.

FIG. 4.- Distribución dimensional de las nanopartículas de hierro en plasma de helio. Intensidad de la corriente de descarga: $350 \mathrm{~A}(\mathrm{cc})$.

Liquid matrix samples (sodium 2-diethy-sulfonsuccinate) containing collected nanoparticles were studied by electron transmission microscopy in order to determine the size distribution. The method allows a resolution up to $0.5 \mathrm{~nm}$ with a magnification up to $6 \cdot 10^{4}$. The examined sample should be based on a transparent support without internal structure, which should resist the high energy electron beam. The support is positioned on an electrolytic copper grid, which enhances its resistance to the electron beam. The transparent support should contain a thin layer of particles to avoid agglomerate formation which may alter the measurements.

Good results were obtained using (21)

- a collodium support of maximum $20 \mathrm{~nm}$ thickness

- a 500-800 mesh metallic grid,

- particle layer diluted $1 / 10,000$ in the carrier liquid.

The increase of the gas pressure in the vaporisation chamber gives rise to an increase of the density of the crystallization centres, as well as their agglomeration. As a result, larger particles are obtained at higher gas pressure. Since the helium enthalpy is smaller with respect to argon, different metal vaporization rates are achieved. In helium gas, the metal vaporization rate is, larger when compared to argon and consequently, on the same vaporization center (at the same gas pressure in the chamber), a large helium vapour amount is condensed, compared to argon. Consequently, when using the same gas relative pressure, larger metal particles are obtained in helium atmosphere then in argon.

\subsection{Non-transferred arc regime}

In the non-transferred arc regime, the plasma jet is formed as the result of electric discharge between the cathode 3 and the nozzle 1 (Fig. 1) in argon medium. Powders or aerosols are introduced in the plasma jet through the pressure equilibration chamber 6 .

Thermal decomposition reactions are produced when solid or liquid particles are in contact with the plasma jet. The metal vapours are condensed on the gas particles to form metal particles which are trained by the gas into the collecting chamber (Fig. 2 ). These particles are settled in the liquid matrix during the rotation of the collecting chamber. Nanoparticles (Fig. 5) are obtained after thermal decomposition of a $\mathrm{CoCl}_{2}-\mathrm{FeCl}_{2}$ in $\mathrm{Ar}-\mathrm{H}_{2}$ plasma $\left(\mathrm{Ar}+50 \% \mathrm{H}_{2}\right)$.

Their saturation magnetisation is dependent on the cobalt concentration in the Fe-Co alloy (22) and was determined using a vibration sample magnetometer.

Thermal decomposition in argon plasma jet of a solution of 2-ethylhexilmaleat of iron (mass ratio $\mathrm{Fe} / \mathrm{C}$ of 1/5 ) conducted to formation of crystalline or amorphous graphite nanoparticles (20 and 21). The shape and dimensions of particles are shown in figure 6 , while their dimensional distribution is given in figure 7.

The described methods of nanoparticle production may be combined to produce nanoparticles of various chemical composition.

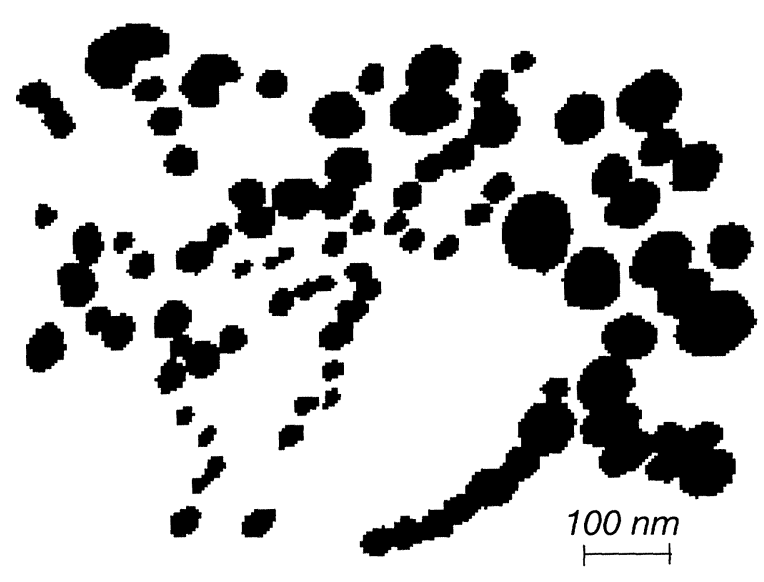

FIG. 5.- Fe-Co nanoparticles.

FIG. 5.- Nanopartículas de Fe-Co. 


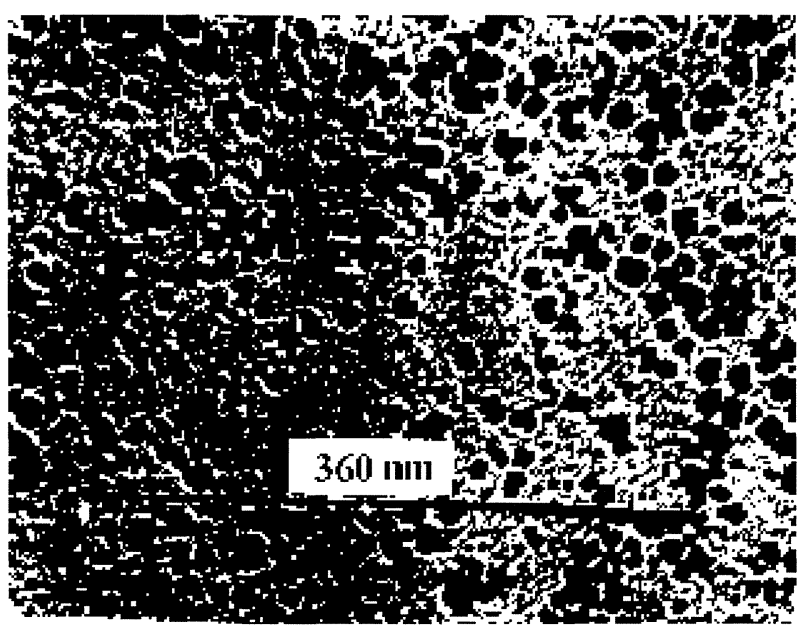

FIG. 6.- Electron microgrph of graphite nanoparticles obtained by argon plasma jet.

FIG. 6.- Nanopartículas de grafito obtenidas en el chorro de plasma.

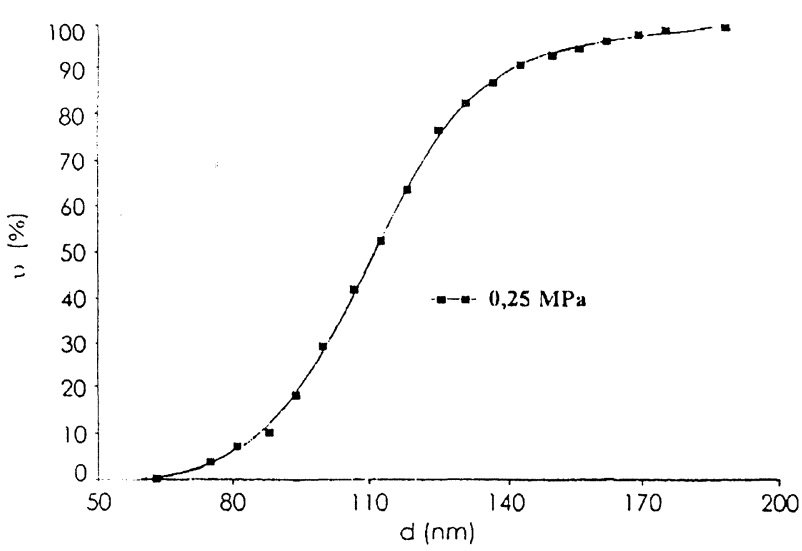

FIG. 7.- Dimensional distribution of graphite nanoparticles.

FIG. 7.- Distribución dimensional de las nanopartículas de grafito.

\section{CONCLUSIONS}

The device presented in figure 1 produces nanoparticles of various kinds using two distinct methods, which may be also combined: thermal decomposition and vaporization of metals.

The device is constructed using a set of functional blocks; it has good fiability and operational safety and easy maintenance.
The dimensional distribution is dependent on the relative gas pressure and its composition, as well as on the plasma arc regime.

\section{REFERENCES}

(1) Whitesides, G.M., Mathias, J.P. and Seto, T.C.R. Science, 254, 1991: 112-1318.

(2) Hayashi, C. Physics Today. Dec. 1987: 45-51.

(3) Gangopadhyay, S. and Hadjipamayis, G.C. Nanostructured Materials 1, 1992: 77-81.

(4) Herzer, G. and Warlimont, H. Nanostructured Materials 1, 1992: 263-268.

(5) Shull, R.D. and Bennett, L.H. Nanostructured Materials 1, 1992: 83-88.

(6) Nakatani, I. and HiJikata, M. J. Magn. Mater. 122, 1993: 10-14.

(7) Provenzano, Y. and Louat, N.P., Nanostructured Materials 1, 1992: 89-94.

(8) Sundaram, M. and Chalmers S.A. Science, 254. Dec. 1991: 1326-1333.

(9) 'GLEITER, H. Nanostructured Materials 1, 1992: 1-19.

(10) Vladimirsky, M.A. and Kuznetsov, A.A. Proceeding of the Sixth International Conference, Paris 20-22 Jul. 1992: 371-373.

(11) Matsunawa, A. and Katayama, S. Trans. JWRI, 19 (1), 1990: 137-147.

(12) KIKUCHI, Y. and MAtsuda, F. Trans JWRI, 22 (2), 1995: 249-256.

(13) SAKKA, Y. and OHNo, S. Nanostructured Materials 7 (3), 1996: 341-353.

(14) Kikuchi, Y. and Matsuda, F. Trans. JWRI, 23 (2), 1994: 175-179.

(15) Wagner, M. and Murty, B.S. Mat. Res. Symp. Proc., 457, 1997: 149-154.

(16) Yoshizawa, A. Patent. 84038050. France ,1984.

(17) Nakatani. I. and Furubayashi, T. J. Magn. Magn. Mater. 85, 1990: 11-13.

(18) BICA, I. Romanian Reports in Physics, 47 (35), 1995: 273-279.

(19) Trusculescu, M. and Jild, M. Hydraulic and Hydrodinamic Machines Conference 7, 1985: 23-30.

(20) Bica, I. and Muscutariu, I. Rev. Metal. Madrid, 32 (5), 1996: 298-302.

(21) BICA, I. Studia Univ. Babes Bolyai-Cluj-Napoca, Physica 40 (1) 1995: 73-79.

(22) Kishimoto, M., Nakazumi, T., Otani, N. and Sueyoshi, T. IEEE Trans Magn. 27 (6), 1991: 46454647. 